\title{
Phase I Study of the Pan-PI3K Inhibitor Buparlisib in Adult Chinese Patients with Advanced Solid Tumors
}

\author{
YI-LONG WU ${ }^{1}$, LI ZHANG ${ }^{2}$, LUCIA TRANDAFIR ${ }^{3}$, TUOCHUAN DONG ${ }^{4}$, \\ VINCENT DUVAL ${ }^{5}$, KATHARINE HAZELL ${ }^{5}$ and BINGHE XU ${ }^{6}$ \\ ${ }^{1}$ Guangdong Lung Cancer Institute, Guangdong General Hospital and Guangdong \\ Academy of Medical Sciences, Guangzhou, P.R. China; \\ ${ }^{2}$ Sun Yat-Sen University Cancer Center, Guangzhou, P.R. China; \\ ${ }^{3}$ Novartis Pharma S.A.S., Paris, France; \\ ${ }^{4}$ Novartis Pharmaceutical Corporation, East Hanover, NJ, U.S.A.; \\ ${ }^{5}$ Novartis Pharma AG, Basel, Switzerland; \\ ${ }^{6}$ National Cancer Center/Cancer Hospital, Chinese Academy of Medical \\ Sciences and Peking Union Medical College, Beijing, P.R. China
}

\begin{abstract}
Background/Aim: The phosphatidylinositol-3kinase (PI3K) signaling pathway is frequently activated in cancer. Buparlisib (BKM120), an oral pan-PI3K inhibitor, inhibits proliferation of human cancer in preclinical models. Studies of buparlisib in Western and Japanese adults with advanced solid tumors established a recommended dose of $100 \mathrm{mg} /$ day and showed an acceptable safety profile and evidence of efficacy. This phase I dose-escalation/expansion study aimed to establish the maximum tolerated dose (MTD) of single-agent, once daily oral buparlisib in Chinese patients with advanced solid tumors. Materials and Methods: Patients ( $n=32$; primary tumor site: lung $(n=15)$, breast $(n=10)$ or head and neck $(n=7) ; \geq 2$ prior lines of antineoplastic therapy $(n=26))$ received $80 \mathrm{mg}(n=15)$ or $100 \mathrm{mg}(n=17)$ daily buparlisib. Results: Five patients experienced dose-limiting toxicities: grade $(G) 3$ depression $(n=1), G 2$ hyperglycemia $(n=3)$ and $G 3$ hyperglycemia $(n=1)$. Most frequent buparlisibrelated adverse events were hyperglycemia $(n=18 ; 56 \%)$, alanine aminotransferase (ALT) and aspartate aminotransferase (AST) increase $(n=9 ; 28 \%)$, as well as anxiety ( $n=6 ; 19 \%)$; most common buparlisib-related G3/4 adverse events: hyperglycemia $(n=3 ; 9 \%), A L T$ and AST increase $(n=2 ; 6 \%)$, as well as gamma-glutamyltransferase
\end{abstract}

Correspondence to: Binghe $\mathrm{Xu}, \mathrm{MD}, \mathrm{Ph} . \mathrm{D}$. ., National Cancer Center/Cancer Hospital, Chinese Academy of Medical Sciences and Peking Union Medical College, No. 17, Panjiayuan Nanli, Chaoyang District, Beijing 100021, P.R. China. Tel: +86 1087788826, Fax: +86 1087715711,e-mail: xubinghe@medmail.com.cn

Key Words: Buparlisib, phosphatidylinositol-3-kinase, breast cancer, head and neck cancer, lung cancer. increase $(n=2 ; 6 \%)$. Best response was stable disease $(S D)$ in 10 patients (31\%). Conclusion: The MTD of buparlisib was declared as $100 \mathrm{mg} /$ day. Safety, efficacy and pharmacokinetic data from this study were similar to those previously reported in Western and Japanese populations.

The phosphatidylinositol-3-kinase (PI3K) signaling pathway regulates a diverse range of cellular processes, including proliferation, survival, protein synthesis, glucose metabolism, migration and angiogenesis (1). The PI3K pathway is the most frequently activated signaling pathway in human cancer. Increases in pathway activity can occur via several mechanisms, including mutation or amplification of upstream regulators, including growth factor receptors, activating mutations in the $P I K 3 C A$ gene that encodes the PI3K p $110 \alpha$ isoform and loss of the negative regulator of PI3K signaling and tumor suppressor phosphatase and tensin homolog (PTEN) (1-4). Activation of the PI3K pathway plays an important role in tumor formation and growth and can cause resistance to anticancer agents, including chemotherapy, endocrine therapy and other targeted therapies $(5,6)$. The critical signaling role played by PI3K in cancer cells makes this enzyme a valid therapeutic target.

Buparlisib (BKM120) is an oral, pan-PI3K inhibitor that targets all four class I isoforms of PI3K and can inhibit both wild-type and mutant versions of the protein at nanomolar concentrations (7). Buparlisib decreases PI3K signaling, promotes apoptosis and prevents cell proliferation in a variety of human cancer cell lines with and without constitutive PI3K activation and causes tumor growth inhibition and regression in xenograft tumor models (7). The first-in-human phase I study of buparlisib in Western adult patients with advanced solid tumors identified the maximum tolerated dose (MTD) 
as $100 \mathrm{mg}$ /day during dose escalation (8), that was confirmed in the subsequent dose-expansion part of the study (9). A similar phase I study of buparlisib in adult Japanese patients with advanced solid tumors also established a recommended dose of $100 \mathrm{mg} /$ day (10). Buparlisib showed an acceptable safety profile as a single agent in both studies with common treatment-related adverse events (AEs), including hyperglycemia, diarrhea, rash, decreased appetite, mood alteration and abnormal hepatic function (8-10). Single-agent buparlisib showed preliminary evidence of efficacy in both patient populations in metastatic breast cancer and other types of solid tumors (8-10). This phase I study was undertaken to establish a recommended dose for future development of buparlisib in the Chinese population.

\section{Materials and Methods}

Study design and treatment. This was a phase I, open-label, doseescalation and -expansion study (ClinicalTrials.gov Identifier: NCT01626209) of single-agent buparlisib administered orally once daily in Chinese patients with advanced solid tumors. The primary objective was to establish the MTD/recommended phase II dose (RP2D) of single-agent buparlisib in adult Chinese patients with advanced solid tumors. Secondary objectives were to investigate the safety, tolerability, pharmacokinetic (PK) profile and clinical efficacy of buparlisib as a single agent in this patient population. During the dose-escalation period, at least three evaluable patients were to be enrolled at each dose level, to be expanded to -at leastsix evaluable patients at the level in which the MTD/RP2D was reached. Two dose levels were to be tested: $80 \mathrm{mg} /$ day and $100 \mathrm{mg} /$ day, each in 28-day treatment cycles. An adaptive Bayesian logistic regression model for dose escalation with overdose control (EWOC) was used to guide the dose-escalation part of the study to estimate the MTD/RP2D $(11,12)$. The MTD was defined as the highest drug dosage not causing a medically unacceptable doselimiting toxicity (DLT) in more than $33 \%$ of the treated patients in the first cycle of treatment and was estimated based on clinical and PK considerations. Patients were treated until disease progression, unacceptable toxicity, investigator's decision or until they refused further study treatment. Informed consent was obtained from each patient prior to enrollment and the study protocol and all amendments were reviewed by the Independent Ethics Committee or Institutional Review Board at each study site. The study was conducted according to the International Conference on Harmonization Harmonized Tripartite Guidelines for Good Clinical Practice, with applicable local regulations (including European Directive 2001/20/EC and US Code of Federal Regulations Title 21) and with the ethical principles laid down in the Declaration of Helsinki.

Patients' eligibility. Adult Chinese patients with advanced unresectable breast cancer or advanced carcinoma with squamous cell histology (including non-small cell lung cancer, squamous cell carcinoma of the head and neck and esophageal cancer) whose disease had progressed on (or who had been unable to tolerate) standard therapy or for whom no standard therapy existed were eligible for this study. Other key inclusion criteria were measurable and/or non-measurable disease as per Response
Evaluation Criteria in Solid Tumors (RECIST) v1.1 guidelines; availability of a representative archival or fresh tumor biopsy; Eastern Cooperative Oncology Group (ECOG) performance status (PS) $\leq 2$; and adequate bone marrow and organ function. Patients were excluded if they had received previous treatment with a PI3K inhibitor; symptomatic central nervous system (CNS) metastases; concurrent treatment with another approved or investigational antineoplastic therapy; increasing or chronic treatment with immunosuppressive agents, such as corticosteroids; active cardiac disease or a history of cardiac dysfunction; Fridericia's corrected QT $>480 \mathrm{~ms}$ on screening electrocardiogram; impairment of gastrointestinal (GI) function or GI disease that may significantly alter the absorption of buparlisib; unresolved diarrhea of Common Terminology Criteria for Adverse Events (CTCAE) grade 2 or greater; patient health questionnaire-9 (PHQ-9) score $\geq 12$ or a positive response to PHQ-9 question 9 relating to suicidal ideation; generalized anxiety disorder 7 (GAD-7) mood scale score $\geq 15$; a documented or current major depressive episode or other specified psychiatric disorders.

Definition of dose-limiting toxicity (DLT). A DLT was defined as an $\mathrm{AE}$ or abnormal laboratory value that fulfilled all of the following criteria: unrelated to disease, disease progression or concomitant medications; occurrence within 28 days following the first dose of buparlisib; meeting any of the criteria in Table I.

Study assessments. Safety assessments consisted of monitoring by physical examination vital signs, weight, ECOG PS, electrocardiogram, laboratory evaluations and assessment of patientrated mood scales (PHQ-9 and GAD-7), in addition to the recording of all serious and non-serious AEs using CTCAE version 4.03. Laboratory evaluations included hematology, blood chemistry, urinalysis and glucose monitoring. For PK assessments, blood samples for buparlisib plasma concentration-time profiles were collected for all study patients on Days 1,8 and 28 of Cycle 1 predose and at $0.5,1,1.5,2,3,4,6,8$ and 24 hours post-dose, as well as on Day 1 of Cycle 3 and every other cycle thereafter, pre-dose and 2-4 h post-dose. Buparlisib in plasma was analyzed by liquid chromatography-tandem mass spectrometry (limit of quantification $1.0 \mathrm{ng} / \mathrm{ml})$. PK parameters were determined using noncompartmental methods (WinNonlin ${ }^{\circledR}$ Pro version 5.2 or Phoenix ${ }^{\circledR}$ WinNonlin ${ }^{\circledR}$ version 6.0 (Pharsight, Mountain View, CA, USA)). For biomarker assessments, archival or fresh tumor samples were investigated for aberrations of the PI3K pathway by analysis of PIK3CA mutations using gene sequencing and PTEN protein expression level using immunohistochemistry. For efficacy assessments, radiologic assessment of tumor lesions using computed tomography (CT) or magnetic resonance imaging (MRI) was performed at baseline and every 8 weeks thereafter. Tumor response was assessed using RECIST v1.1.

\section{Results}

Patients' characteristics and treatment. Between July 2012 and April 2014, 32 Chinese patients with advanced solid tumors were enrolled and treated with buparlisib at three centers in China: 15 patients received $80 \mathrm{mg}$ buparlisib and 17 patients received $100 \mathrm{mg}$ buparlisib once daily (Table II). The median age of patients was 52 (range $=24-75$ ) years, 
Table I. Criteria for defining dose-limiting toxicities.

Toxicity

Toxicity leading to skipped/delayed dose

Re-occurred toxicity

Hematological

Renal

Hepatic

Endocrine (hyperglycemia is not graded per CTCAE v4.03)

Metabolic/Laboratory

Pancreatitis

Cardiac

Neurotoxicity (other than mood alterations) Mood alteration

Dermatologic

Other adverse events
Any of the following criteria

An AE (except for alopecia) of any grade, considered to be related to the study drug, leading to a dose interruption of more than 7 consecutive days, despite supportive treatment, will be considered to be a DLT

If the 2nd occurrence of an initially non-dose limiting toxicity (e.g. grade 1 neutropenia that resolved within 7 days at 1 st occurrence) leads to a dose reduction within 28 days of the first 28 days of the first dose of buparlisib, this will be considered a DLT

CTCAE grade 4 neutropenia

CTCAE grade 4 thrombocytopenia

Febrile neutropenia (ANC $<1.0 \times 10^{9} / 1$, with a single temperature $\geq 38.3^{\circ} \mathrm{C}$

or a sustained temperature of $\geq 38^{\circ} \mathrm{C}$ for more than 1 hour) CTCAE grade $\geq 3$

CTCAE grade $\geq 3$ serum creatinine

Total bilirubin $\geq 2.0 \times$ ULN to $\leq 3.0 \times$ ULN for $>7$ consecutive days.

AST or ALT CTCAE grade $\geq 3$ in conjunction with blood bilirubin CTCAE grade $\geq 2$ of any duration CTCAE grade $\geq 3$ total bilirubin

CTCAE grade 3 AST or ALT for $>7$ consecutive days

CTCAE grade 4 AST or ALT

Grade 2 hyperglycemia (>8.89-13.89 mmol/l or $160-250 \mathrm{mg} / \mathrm{dl} \mathrm{FPG}$; confirmed with a repeat FPG within 24 hours) that does not resolve to normal within 14 consecutive days (after initiation of adequate antidiabetic treatment)

Grade $\geq 3$ hyperglycemia ( $>13.89 \mathrm{mmol} / \mathrm{l}$ or $250 \mathrm{mg} / \mathrm{dl} \mathrm{FPG}$;

confirmed with a repeat FPG within 24 hours)

CTCAE grade 3 asymptomatic amylase and/or lipase for $>7$ consecutive days

CTCAE grade 3 GGT elevation

CTCAE grade 4 asymptomatic amylase and/or lipase

CTCAE grade 4 GGT elevation

CTCAE grade $\geq 2$

Cardiac toxicity $\geq$ CTCAE grade 3 or cardiac event that is symptomatic or requires medical intervention

Clinical signs of cardiac disease, such as unstable angina or myocardial infarction, or troponin $\geq$ CTCAE grade 3

At least one CTCAE grade level increase

CTCAE grade 2 mood alteration that does not resolve to $\leq$ grade 1 within 14 days despite medical treatment (for anxiety only, if worsened from baseline)

CTCAE grade $\geq 3$ mood alteration

CTCAE grade $\geq 2$ photosensitivity

CTCAE grade 3 rash for $>7$ consecutive days despite skin toxicity treatment

CTCAE grade 4 rash

CTCAE grade $\geq 3$ adverse events (excluding CTCAE grade $\geq 3$ lymphopenia or

CTCAE grade $\geq 3$ elevations in alkaline phosphatase)

CTCAE grade $\geq 3$ vomiting/nausea $\geq 48$ hours, despite the use of antiemetic therapy

CTCAE grade $\geq 3$ diarrhea $\geq 48$ hours, despite the use of antidiarrheal therapy

CTCAE grade 3 fatigue (asthenia) for $>7$ consecutive days

CTCAE grade 4 fatigue (asthenia)

ALT, Alanine aminotransferase; ANC, absolute neutrophil count; AST, aspartate aminotransferase; CTCAE, Common Terminology Criteria for Adverse Events; DLT, dose-limiting toxicity; FPG, fasting plasma glucose; GGT, gamma-glutamyltransferase; ULN, upper limit of the normal range. aCTCAE grade $\geq 3$ anemia is not considered a DLT unless judged to be a hemolytic process secondary to the study drug. CTCAE grade $\geq 3$ lymphopenia is not considered a DLT unless clinically significant.

$56 \%$ (18 of 32) were female and $91 \%$ (29 of 32) had an ECOG PS of $0-1$. The predominance of tumor type was nonsmall cell lung cancer $(n=15)$, breast $(n=10)$ or squamous cell cancer of head and neck $(n=7)$. This patient population was heavily pre-treated, with $81 \%(n=26)$ and $38 \%(n=12)$ having received at least two or four prior lines of antineoplastic therapy, respectively, including at least one line of therapy in the metastatic setting in $84 \%(n=27)$ of patients. Seven patients in the study were reported to have PI3K pathway activation: two due to PIK3CA mutation, four due to loss of PTEN expression and one due to both a PIK3CA mutation and loss of PTEN expression. Nineteen patients $(59 \%)$ had progressed within 12 months following the initial diagnosis. 
Table II. Baseline patients' and disease characteristics.

\begin{tabular}{|c|c|c|c|}
\hline & $\begin{array}{c}\text { Buparlisib } \\
80 \mathrm{mg} \\
\mathrm{N}=15\end{array}$ & $\begin{array}{c}\text { Buparlisib } \\
100 \mathrm{mg} \\
\mathrm{N}=17\end{array}$ & $\begin{array}{r}\text { Total } \\
\mathrm{N}=32\end{array}$ \\
\hline \multicolumn{4}{|l|}{ Age (years) } \\
\hline Median & 54 & 51 & 52 \\
\hline Range & $31-75$ & $24-72$ & $24-75$ \\
\hline \multicolumn{4}{|l|}{ Gender, n (\%) } \\
\hline Female & $8(53)$ & $10(59)$ & $18(56)$ \\
\hline Male & $7(47)$ & $7(41)$ & $14(44)$ \\
\hline \multicolumn{4}{|c|}{$\begin{array}{l}\text { Baseline ECOG } \\
\text { performance status, n (\%) }\end{array}$} \\
\hline 0 & 0 & $1(6)$ & $1(3)$ \\
\hline 1 & 13 (87) & $15(88)$ & $28(88)$ \\
\hline 2 & $2(13)$ & $1(6)$ & $3(9)$ \\
\hline \multicolumn{4}{|c|}{ Primary site of cancer, $\mathrm{n}(\%)$} \\
\hline Breast & $3(20)$ & $7(41)$ & $10(31)$ \\
\hline Head and neck & $3(20)$ & $4(24)$ & $7(22)$ \\
\hline Lung & $9(60)$ & $6(35)$ & $15(47)$ \\
\hline \multicolumn{4}{|c|}{$\begin{array}{l}\text { Number of prior lines of } \\
\text { antineoplastic therapy, } \mathrm{n}(\%)\end{array}$} \\
\hline 1 & $2(13)$ & $4(24)$ & $6(19)$ \\
\hline 2 & $4(27)$ & $3(18)$ & $7(22)$ \\
\hline 3 & $4(27)$ & $3(18)$ & $7(22)$ \\
\hline$\geq 4$ & $5(33)$ & $7(41)$ & $12(38)$ \\
\hline \multicolumn{4}{|c|}{ PIK3CA mutation, $\mathrm{n}(\%)$} \\
\hline Yes & $1(7)$ & $2(12)$ & $3(9)$ \\
\hline No & $9(60)$ & $12(71)$ & $21(66)$ \\
\hline Unknown & $1(7)$ & $2(12)$ & $3(9)$ \\
\hline Missing ${ }^{\mathrm{a}}$ & $4(27)$ & $1(6)$ & $5(16)$ \\
\hline \multicolumn{4}{|c|}{ PTEN negative, $\mathrm{n}(\%)$} \\
\hline Yes & $2(13)$ & $3(18)$ & $5(16)$ \\
\hline No & $9(60)$ & $13(77)$ & $22(69)$ \\
\hline Unknown & 0 & 0 & 0 \\
\hline Missing $^{\mathrm{a}}$ & $4(27)$ & $1(6)$ & $5(16)$ \\
\hline
\end{tabular}

ECOG, Eastern Cooperative Oncology Group. ${ }^{a}$ Damaged samples not suitable for analysis.

DLTs and MTD. Twelve patients were included in the dosedetermining set (DDS) used to establish the MTD: four in the 80-mg buparlisib group and eight in the 100-mg buparlisib group. Five patients experienced DLTs during the study. Two DLTs occurred in the dose-escalation part of the study and were grade 3 depression ( $\mathrm{n}=1,80-\mathrm{mg}$ group) and grade 2 hyperglycemia ( $n=1,100-m g$ group). Based on the results from patients in the DDS, the MTD of buparlisib was declared as $100 \mathrm{mg} / \mathrm{day}$. Additional patients were enrolled into the dose-expansion part of the study in parallel dose groups ( $80 \mathrm{mg}$ and $100 \mathrm{mg}$ ) for evaluation of the safety and tolerability of buparlisib. Three DLTs occurred in the doseexpansion part of the study; all were hyperglycemia in the $80-\mathrm{mg}$ group ( $\mathrm{n}=2$ grade 2 hyperglycemia; $\mathrm{n}=1$ grade 3 hyperglycemia). The MTD of buparlisib was confirmed at $100 \mathrm{mg} /$ day with an overall frequency of DLTs at this dose level of $3 \%$.
Safety and tolerability. All patients experienced at least one $\mathrm{AE}$ regardless of relationship to the study drug. These included hyperglycemia in 19 patients (59\%), increased alanine aminotransferase (ALT) in 14 patients (44\%), increased aspartate aminotransferase (AST) in 13 patients (41\%; 12 patients had an increase in both ALT and AST $(38 \%))$ and decreased appetite in 10 patients (31\%). Study drug-related AEs were seen in 28 patients (88\%), including hyperglycemia in 18 patients (56\%), ALT and AST increase in the same nine patients ( $28 \%$ each), as well as anxiety in six patients (19\%; Table III).

Eight patients (25\%) experienced grade 3/4 AEs that were suspected to be related to buparlisib; these included hyperglycemia in three patients (9\%), ALT and AST increase in the same two patients (6\% each) and gammaglutamyltransferase increase in two patients (3\%). The frequency of treatment-related grade 3/4 AEs was similar at the two dose levels tested: $27 \%$ of patients treated at $80 \mathrm{mg}$ and $24 \%$ treated at $100 \mathrm{mg}$ experienced grade $3 / 4$ AEs. Four patients in each dose group experienced at least one serious AE (SAE) regardless of relationship to the study drug. Two patients (12\%) in the 100-mg group experienced SAEs suspected to be study drug-related, including one patient with a grade 3 suicide attempt and one patient with grade 2 pneumonitis.

Irrespective of causality, AEs led to buparlisib discontinuation in seven patients (22\%). These included three patients in the 80-mg group (one case each of grade 3 pneumonia, grade 4 dyspnea and grade 4 hemoptysis) and four patients in the 100-mg group (one case each of grade 2 pulmonary tuberculosis, grade 2 hyperglycemia, grade 2 pneumonitis and grade 3 suicide attempt). In addition, 11 patients (34\%) experienced AEs requiring dose interruption or dose adjustments: five patients (33\%) in the $80-\mathrm{mg}$ group and six patients $(35 \%)$ in the $100-\mathrm{mg}$ group; of which hyperglycemia in four patients was the most frequent (three patients in the $80-\mathrm{mg}$ group and one patient in the $100-\mathrm{mg}$ group). Other reasons for dose interruption or change were pyrexia, depression, anemia, AST or ALT increase, decreased platelets, thrombocytopenia, hiccups, decreased appetite and dyspnea ( $n=1$ each). Eight deaths (25\%; four in each dose group) occurred during the study; none were suspected to be study drug-related. Seven patients died due to disease progression and one patient died due to pneumonia. The median duration of exposure to buparlisib was 48 days in the 80-mg group and 57 days in the 100-mg group. The median relative dose intensity for all patients was $100 \%$.

Pharmacokinetics. After both single and repeated doses, the absorption of buparlisib was rapid in both treatment groups with a median $\mathrm{T}_{\max }$ of 1-1.7 $\mathrm{h}$ (Table IV). Following a single dose of $80 \mathrm{mg}$ buparlisib, the mean $\mathrm{C}_{\max }$ was $838 \mathrm{ng} / \mathrm{ml}$, 
Table III. Most common adverse events (>10\%) thought to be related to study treatment.

\begin{tabular}{|c|c|c|c|c|c|c|}
\hline \multirow[t]{2}{*}{ Preferred term, n (\%) } & \multicolumn{2}{|c|}{$\begin{array}{l}\text { Buparlisib } 80 \mathrm{mg} \\
\qquad \mathrm{N}=15\end{array}$} & \multicolumn{2}{|c|}{$\begin{array}{l}\text { Buparlisib } 100 \mathrm{mg} \\
\mathrm{N}=17\end{array}$} & \multicolumn{2}{|c|}{$\begin{array}{l}\text { Total } \\
\mathrm{N}=32\end{array}$} \\
\hline & All grades & Grade $3 / 4$ & All grades & Grade $3 / 4$ & All grades & Grade $3 / 4$ \\
\hline Total & $14(93)$ & $4(27)$ & $14(82)$ & $4(24)$ & $28(88)$ & $8(25)$ \\
\hline Hyperglycemia & $10(67)$ & $2(13)$ & $8(47)$ & $1(6)$ & $18(56)$ & $3(9)$ \\
\hline ALT increased & $3(20)$ & $1(7)$ & $6(35)$ & $1(6)$ & $9(28)$ & $2(6)$ \\
\hline AST increased & $3(20)$ & $1(7)$ & $6(35)$ & $1(6)$ & $9(28)$ & $2(6)$ \\
\hline Anxiety & $5(33)$ & 0 & $1(6)$ & $1(6)$ & $6(19)$ & $1(3)$ \\
\hline Depression & $4(27)$ & $1(7)$ & 0 & 0 & $4(13)$ & $1(3)$ \\
\hline Blood bilirubin increased & $3(20)$ & 0 & $1(6)$ & 0 & $4(13)$ & 0 \\
\hline Fatigue & $3(20)$ & 0 & $1(6)$ & 0 & $4(13)$ & 0 \\
\hline Decreased appetite & $2(13)$ & 0 & $2(12)$ & 0 & $4(13)$ & 0 \\
\hline Hypocalcemia & $2(13)$ & 0 & $2(12)$ & 0 & $4(13)$ & 0 \\
\hline Insulin c-peptide increased & $2(13)$ & 0 & $2(12)$ & 0 & $4(13)$ & 0 \\
\hline Rash & $1(7)$ & 0 & $3(18)$ & 0 & $4(13)$ & 0 \\
\hline
\end{tabular}

ALT, Alanine aminotransferase; AST, aspartate aminotransferase.

Table IV. Pharmacokinetic profile of oral buparlisib in Chinese patients in Cycle 1.

\begin{tabular}{lcccccccc}
\hline Dose $(\mathrm{mg} / \mathrm{day})$ & $\mathrm{Day}$ & $\mathrm{n}$ & $\mathrm{T}_{\max }(\mathrm{h})$ & $\mathrm{C}_{\max }(\mathrm{ng} / \mathrm{ml})$ & $\mathrm{AUC}_{0-24}(\mathrm{ng} \bullet \mathrm{h} / \mathrm{ml})$ & $\mathrm{T}_{1 / 2}(\mathrm{~h})$ & $\mathrm{R}_{\mathrm{acc}}$ & $\mathrm{CL} / \mathrm{F}(\mathrm{l} / \mathrm{h})$ \\
\hline 80 & 1 & 15 & 1.02 & $838(422)$ & $7,000(2,230)$ & - & - & - \\
& 8 & 14 & 1.00 & $1,470(476)$ & $18,000(6,260)$ & $36.7(13.5)$ & $2.8(0.8)$ & $4.99(1.81)$ \\
100 & 28 & 9 & 1.00 & $1,330(443)$ & $18,000(4,260)$ & $39.3(8.6)$ & $2.9(0.5)$ & $4.71(1.21)$ \\
& 1 & 17 & 1.00 & $994(344)$ & $8,770(2,260)$ & - & - & - \\
& 8 & 16 & 1.73 & $1,980(493)$ & $22,500(5,680)$ & $36.0(10.8)$ & $2.7(0.6)$ & $4.72(1.23)$ \\
& 28 & 13 & 1.50 & $1,880(520)$ & $22,400(6,340)$ & $38.3(13.3)$ & $2.8(0.8)$ & $4.82(1.43)$ \\
\hline
\end{tabular}

$\mathrm{AUC}_{0-24}$, Area under the curve from 0 to $24 \mathrm{~h} ; \mathrm{CL} / \mathrm{F}$, oral clearance; $\mathrm{C}_{\max }$, maximum plasma concentration; $\mathrm{R}_{\mathrm{acc}}$, accumulation rate; $\mathrm{T}_{1 / 2}$, halflife; $\mathrm{T}_{\max }$, time at which maximum plasma concentration is achieved. Values are presented as mean (standard deviation) except for $\mathrm{T}_{\max }$, which is presented as median.

which is approximately $80 \%$ of the mean $\mathrm{C}_{\max }$ observed after a single 100-mg dose, suggesting a proportional increase of $\mathrm{C}_{\max }$ with dose (Table IV). After repeated daily doses of buparlisib, mean $C_{\max }$ was similar at Day 8 and Day 28 for each of the two dose levels with higher values for the 100-mg dose (Table IV). Similarly, the area under the curve (AUC) $0-24$ values were similar at Day 8 and 28 for each of the two doses, again with higher values in the 100mg dose (Table IV). These results are consistent with a $\mathrm{C}_{\max }$ increase proportional to dose and with steady-state for buparlisib being reached after seven days of continuous dosing. The accumulation ratio, calculated based on the $\mathrm{AUC}_{0-24}$ ratio after repeated and single doses, was approximately 2.8 for both doses. Buparlisib displayed linear pharmacokinetics with a similar clearance at the $80-\mathrm{mg}$ and 100-mg doses. The effective buparlisib half-life was also similar across doses, being between 36 and 39 h. The mean buparlisib plasma concentration profiles on Cycle 1 Days 1, 8 and 28 for each dose group are shown in Figure 1.

Efficacy. The reported antitumor activity of single-agent buparlisib was marginal. No patient achieved a complete response $(\mathrm{CR})$ or partial response $(\mathrm{PR})$ to buparlisib during the study (Table V). However, 10 patients (31\%) exhibited stable disease (SD) as their best response (two patients $(13 \%)$ in the $80-\mathrm{mg}$ group and eight patients $(47 \%)$ in the $100-\mathrm{mg}$ group) and one patient $(6 \%)$ with non-measurable disease (in the 100-mg group) had non-CR/non-PD. Nine patients $(28 \%)$ were non-evaluable for best overall response due to the absence of a valid post-baseline assessment. Overall, the disease control rate (SD + non-CR/non-PD) was 34\%: $13 \%$ in the $80-\mathrm{mg}$ group and $53 \%$ in the $100-\mathrm{mg}$ group. The best percentage changes from baseline by PI3K pathway activation status and dose level are presented in 


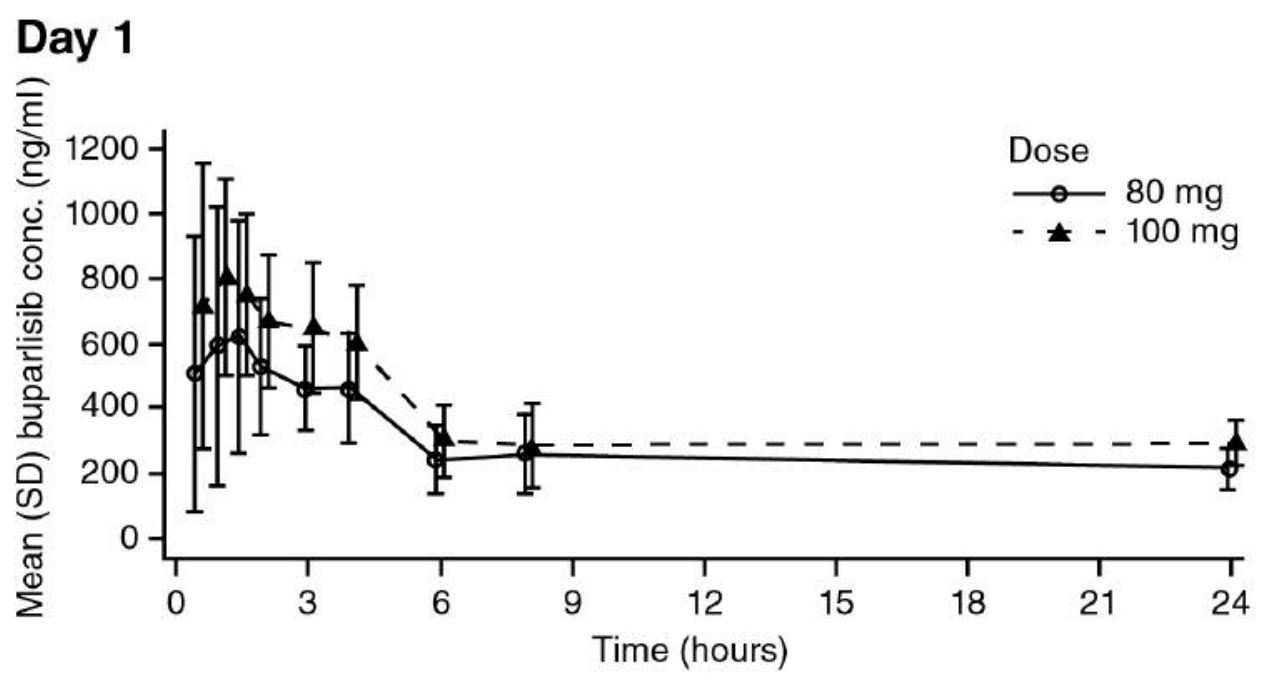

Day 8

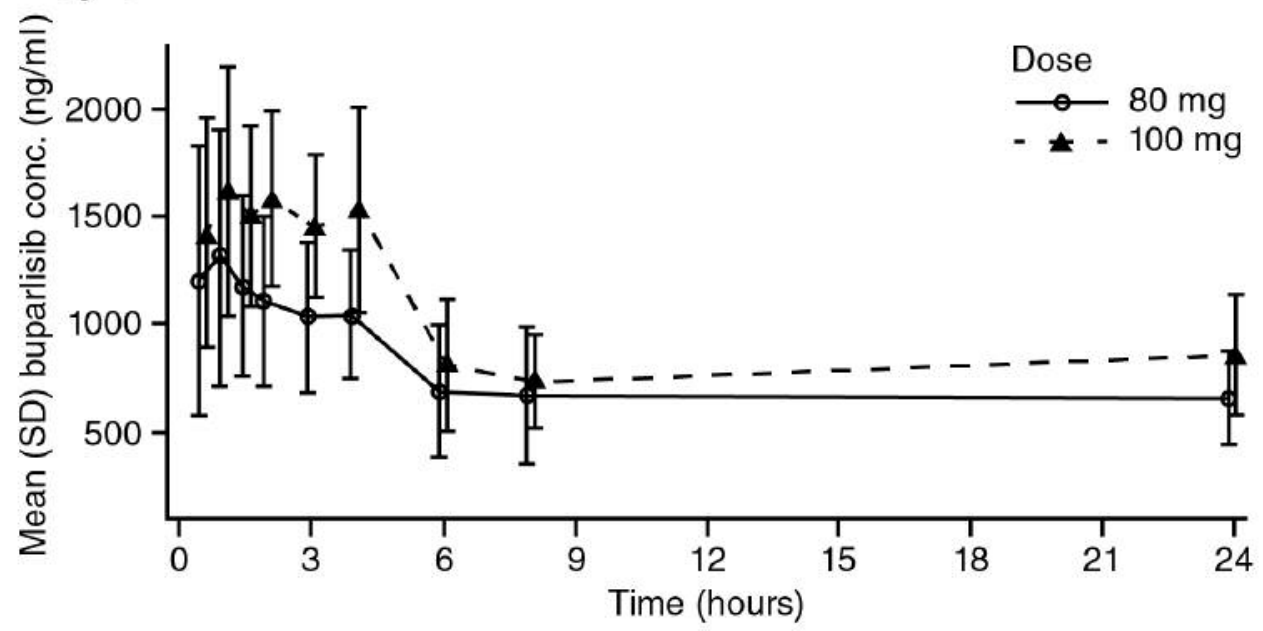

\section{Day 28}

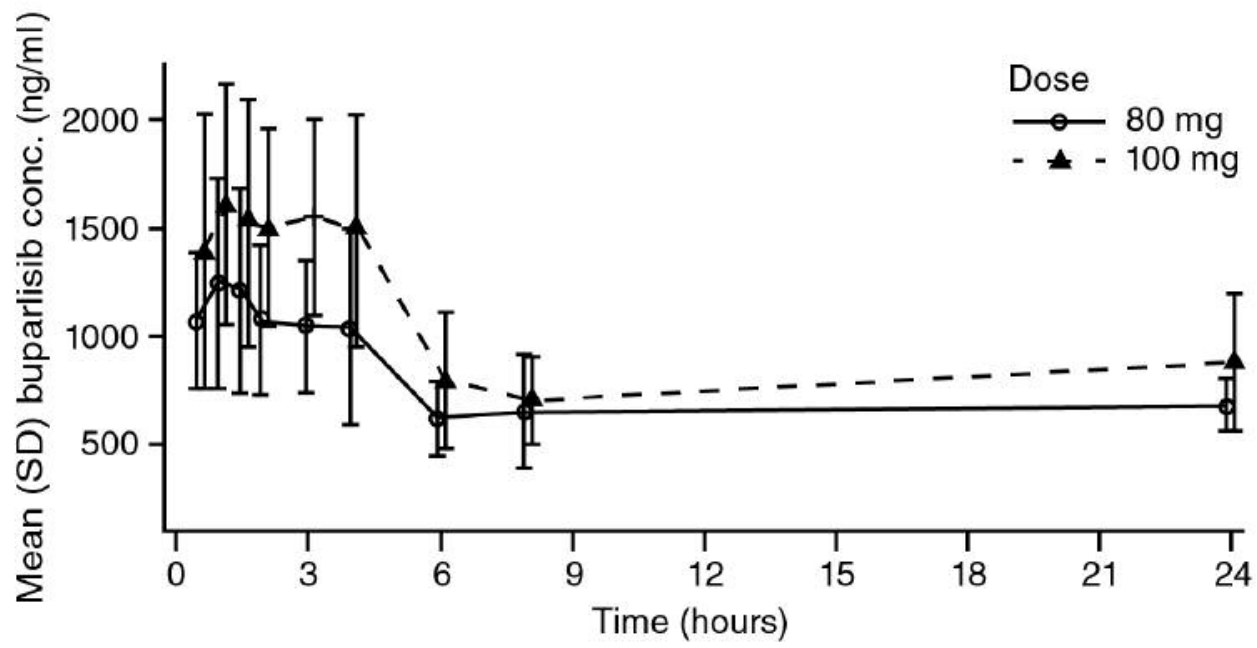

Figure 1. Linear plasma concentration profiles for buparlisib in Chinese patients in Cycle 1. SD, Standard deviation. 


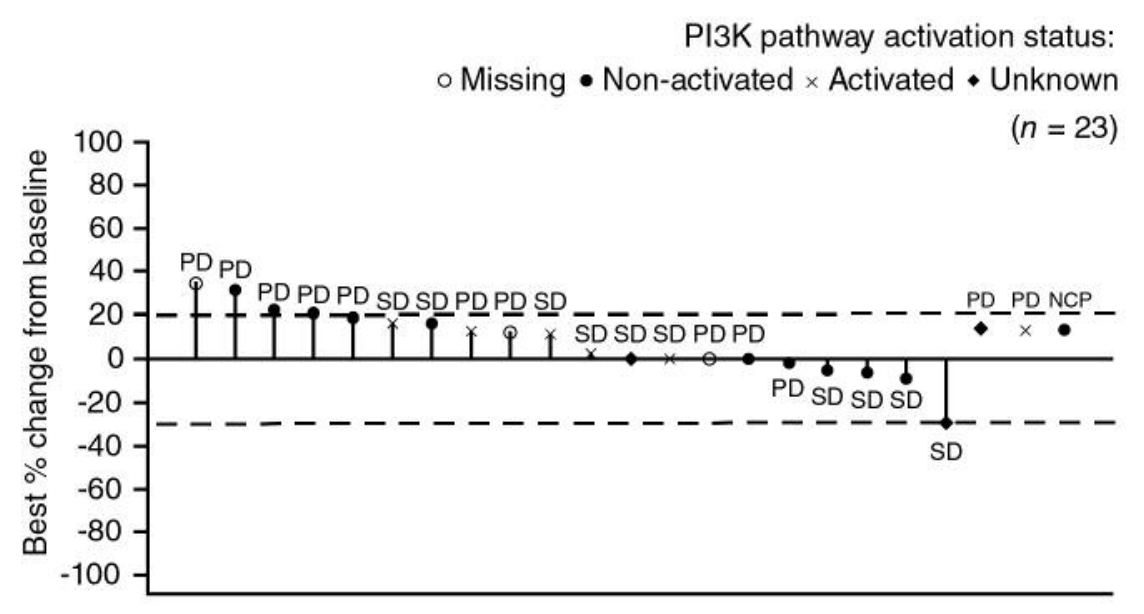

Figure 2. Radiologic response to buparlisib with corresponding status of tumor PI3K activation status. CR, Complete response; NCP, non-CR/non$P D$; $P D$, progressive disease; PI3K, phosphatidylinositol-3-kinase; $P R$, partial response, $S D$, stable disease. Patients with missing best percentage change from baseline and unknown overall response are not included. Unknown indicates patients not qualifying for confirmed CR or PR and without $S D$ after more than 6 weeks or early progression within the first 12 weeks. Missing line denotes a missing best percentage change from baseline.

Figure 2. The median time to disease progression was 1.84 months $(95 \%$ confidence interval $(\mathrm{CI})=0.92-3.38)$ for the 80 -mg group and 2.96 months $(95 \% \mathrm{CI}=1.71-3.61)$ for the 100-mg group.

\section{Discussion}

The primary objective of this phase I study of single-agent buparlisib in adult Chinese patients with advanced solid tumors was to establish the MTD and/or RP2D for this agent. Starting at $80 \mathrm{mg} /$ day (a dose selected based on data for single-agent buparlisib in phase I studies in Western and Japanese patient populations) $(8,10)$, dose escalation established an MTD/RP2D for buparlisib in Chinese patients as $100 \mathrm{mg} /$ day. This is the same dose as that established for single-agent buparlisib in Western and Japanese patients (8, 10). The posterior distribution of DLT rates indicated that $100 \mathrm{mg} /$ day satisfied the EWOC criteria for the recommended dose and, together with safety and PK data, was used to determine the MTD.

The PK profiles observed in the Chinese patients treated with $100 \mathrm{mg} /$ day buparlisib in this study are similar to those observed in Western and Japanese patients $(8,10)$. Buparlisib has been found to be rapidly absorbed after single and repeated doses, with a $\mathrm{T}_{\max }$ of 1-3 $\mathrm{h}$, in all three studies. The effective half-life of buparlisib was approximately $40 \mathrm{~h}$ in Western and Japanese patients compared with $36-39 \mathrm{~h}$ in Chinese patients; steady-state for buparlisib is reached after seven days of continuous dosing in all patient populations studied to date $(8,10)$. After 28 days of buparlisib treatment, mean $\mathrm{C}_{\max }$ and $\mathrm{AUC}_{0-24}$ were similar across Western $\left(\mathrm{C}_{\max }\right.$
Table V. Clinical responses to buparlisib in Chinese patients with advanced solid tumors.

\begin{tabular}{lccc}
\hline $\begin{array}{l}\text { Best overall response, } \\
\mathrm{n}(\%)\end{array}$ & $\begin{array}{c}\text { Buparlisib } \\
80 \mathrm{mg} \\
\mathrm{N}=15\end{array}$ & $\begin{array}{c}\text { Buparlisib } \\
100 \mathrm{mg} \\
\mathrm{N}=17\end{array}$ & $\begin{array}{c}\text { Total } \\
\mathrm{N}=32\end{array}$ \\
\hline $\mathrm{CR}$ or PR & 0 & 0 & 0 \\
$\mathrm{SD}$ & $2(13)$ & $8(47)$ & $10(31)$ \\
Non-CR/non-PD & 0 & $1(6)$ & $1(3)$ \\
Disease control rate & $2(13)$ & $9(53)$ & $11(34)$ \\
$\mathrm{PD}$ & $7(47)$ & $5(29)$ & $12(38)$ \\
Unknown & $6(40)$ & $3(18)$ & $9(28)$ \\
\hline
\end{tabular}

$\mathrm{CR}$, Complete response; PD, progressive disease; PR, partial response; $\mathrm{SD}$, stable disease. ${ }^{\mathrm{a}} \mathrm{In}$ patients with non-measurable disease. ${ }^{b} \mathrm{CR}+\mathrm{PR}+\mathrm{SD}+$ non-CR/non-PD.

$\left.1850 \mathrm{ng} / \mathrm{ml} ; \mathrm{AUC}_{0-24} 22,500 \mathrm{ng} \bullet \mathrm{h} / \mathrm{ml}\right)$, Japanese $\left(\mathrm{C}_{\max } 1790\right.$ $\left.\mathrm{ng} / \mathrm{ml} ; \mathrm{AUC}_{0-24} 25,000 \mathrm{ng} \bullet \mathrm{h} / \mathrm{ml}\right)$ and Chinese patients $\left(\mathrm{C}_{\max }\right.$ $\left.1880 \mathrm{ng} / \mathrm{ml} ; \mathrm{AUC}_{0-24} 22,400 \mathrm{ng} \bullet \mathrm{h} / \mathrm{ml}\right)(8,10)$.

Safety results from this study were also similar to those recorded in Western and Japanese populations (8-10). Three main categories of AEs suspected to be related to buparlisib were: hyperglycemia, liver function abnormalities and mood disorders. Hyperglycemia is considered an on-target, class effect of PI3K inhibitors due to disrupted insulin signaling and reduced glucose uptake and glycogen synthesis as a result of PI3K inhibition $(4,13,14)$. Other PI3K pathway inhibitors for which hyperglycemia has been reported include PKI-587 (PF$05212384)$ and BEZ235 $(15,16)$. In this study, hyperglycemia 
was the most frequently reported $\mathrm{AE}$ suspected to be related to treatment, reported in 18 patients $(56 \%$; grade $3 / 4$ in three patients, 9\%; Table III) and was the most frequent reason for dose interruption. This was slightly higher than the frequency of hyperglycemia suspected to be related to treatment reported in the first-in-human phase I study of buparlisib in Western patients, which was $31 \%$ overall (9). Only one case of grade $3 / 4$ hyperglycemia (7\%; irrespective of relationship to study drug) was reported in the phase I study of buparlisib in Japanese patients but the number of patients in that study was small $(n=15)(10)$. Hyperglycemia was largely manageable with oral antidiabetic agents, such as metformin, and/or with insulin and dose interruptions, combined with careful monitoring of blood glucose levels, as recommended following previous experience $(8,14)$.

Liver function abnormalities suspected to be related to buparlisib treatment were also frequent in this study: increased ALT and AST were seen in the same 9 patients (28\%; grade $3 / 4$ in the same two patients, $6 \%$ ). Increases in transaminase levels have been observed in previous studies of buparlisib (40\% grade 3/4 transaminase increases were reported in Japanese patients and grade 3/4 transaminase increases were also reported in Western patients) and other PI3K pathway inhibitors at varying frequencies $(8,10,15$, 17-22). Further studies may allow characterization of hepatic enzyme perturbation with buparlisib, which may be an ontarget effect of inhibiting PI3K or some other biochemical effect of the compound on hepatocytes. An exploratory analysis into a possible relationship between PK parameters for buparlisib and any increase in risk for liver function test alteration is ongoing (Novartis, unpublished data).

Mood alterations, in the form of anxiety and depression, were recorded in this study. Mood disorders following buparlisib treatment have been observed in other early clinical studies of the agent (8-10) and other buparlisib studies have restricted the enrolment of patients deemed to be at increased risk of psychiatric AEs. Studies of buparlisib have also used the PHQ-9 (depression) and GAD-7 (anxiety) questionnaires to monitor patients and allow timely intervention. Under-activation of the PI3K/AKT/mammalian target of rapamycin (mTOR) pathway has been linked to anxiety and depression (23-25). Notably, decreases in the activity of PI3K and AKT and increases in PTEN protein levels were observed in the ventral prefrontal cortex of depressed suicide victims and depressed non-suicide subjects (26). Buparlisib has been shown to cross the blood-brain barrier and has demonstrated preliminary clinical activity in brain lesions of patients with breast cancer and non-small cell lung cancer, suggesting buparlisib-mediated inhibition of PI3K in the CNS (27). Mood disorders are also commonly associated with cancer diagnoses, with studies estimating that $30 \%-50 \%$ of cancer patients experience psychological symptoms, including adjustment disorders, anxiety or depression $(28,29)$. In this study, the incidence of depression and anxiety was $13 \%$ and $19 \%$, respectively (Table III).

Preliminary signs of clinical efficacy were observed in this study, with 10 patients $(31 \%)$ exhibiting stable disease. The disease control rate reported here $(34 \%)$ is similar to rates seen with buparlisib in other patient populations: $41 \%$ and $40 \%$ in the Western and Japanese patient populations, respectively (9, 10). Although it is possible that buparlisib may show greater efficacy in patients with activated PI3K signaling, this study contained too few patients to determine any correlation between mutation status and response, as has been possible with other targeted therapies, such as the epidermal growth factor receptor (EGFR) inhibitor gefitinib, found to be relatively more effective in patients with EGFR-mutated lung cancer than EGFR-wildtype disease (30), with clear implications for patient selection. Results from previous trials of buparlisib and other PI3K inhibitors have also been inconclusive regarding a correlation between PI3K activation status and clinical response $(8,9,19$, 31-35). Notably, PI3K activation status in this and other clinical studies of PI3K pathway inhibitors has been assessed using PIK3CA mutation and/or loss of PTEN expression in predominantly archival tissue $(8,9,19,31,32)$; however, it is known that PI3K activation can occur independently of these molecular alterations $(1,3)$ and that the mutational status of PI3K can change upon disease recurrence (36). Therefore, further research is needed to determine if PI3K activation status is a predictor of buparlisib response and whether selecting for patients with PI3K activation could improve outcomes with buparlisib. Moreover, additional efforts are required to identify patients with PIK3CA-mutant tumors just prior to the start of study treatment with $\mathrm{PI} 3 \mathrm{~K}$ inhibitors to provide a more accurate assessment of the potential benefit of these agents according to the current molecular status of the tumor. The development of combination strategies targeting multiple pathways is also a potential future approach to achieving more meaningful therapeutic effects given that the single-agent activity seen so far with PI3K inhibitors has been limited (37). In this regard, multiple clinical trials are underway, including phase III studies of buparlisib in combination with fulvestrant in patients with advanced or metastatic hormone receptorpositive breast cancer.

\section{Conclusion}

This phase I dose-escalation and -expansion study has established the MTD of buparlisib in adult Chinese patients with advanced solid tumors as $100 \mathrm{mg} /$ day. Single-agent buparlisib, administered orally, once daily, had an acceptable safety profile and was generally well tolerated in this patient population. The PK profiles and the preliminary signs of clinical efficacy observed in this study of Chinese patients are similar to results from previous studies of buparlisib in Western and Japanese patient populations $(8,10)$. 


\section{Compliance with Ethical Standards Disclosure of Potential Conflicts of Interest}

L.T., T.D., V.D. and K.H. are full-time employees of Novartis Pharmaceuticals Corporation, while V.D. owns shares in Novartis Pharmaceuticals Corporation. Y.W., L.Z. and B.X. have no financial relationships to declare.

\section{Ethical Approval}

All procedures performed in studies involving human participants were in accordance with the ethical standards of the institutional and/or national research committee and with the 1964 Helsinki declaration and its later amendments or comparable ethical standards.

\section{Informed Consent}

Informed consent was obtained from all individual participants included in the study.

\section{Acknowledgements}

The Authors would like to thank the patients who took part in the study and their families, as well as the staff who assisted with the study at each site. This study was sponsored by Novartis Pharmaceuticals Corporation that also provided financial support for medical editorial assistance. We thank Karen Beckett PhD and Abbie Saunders $\mathrm{PhD}$ for medical editorial assistance with this manuscript.

\section{References}

1 Porta C, Paglino C and Mosca A: Targeting PI3K/Akt/mTOR signaling in cancer. Front Oncol 4: 64, 2014.

2 Liu P, Cheng H, Roberts TM and Zhao JJ: Targeting the phosphoinositide 3-kinase (PI3K) pathway in cancer. Nat Rev Drug Discov 8: 627-644, 2009.

3 Jia S, Roberts TM and Zhao JJ: Should individual PI3 kinase isoforms be targeted in cancer? Curr Opin Cell Biol 21: 199-208, 2009.

4 Engelman JA: Targeting PI3K signalling in cancer: Opportunities, challenges and limitations. Nat Rev Cancer 9: 550-562, 2009.

5 McCubrey JA, Steelman LS, Abrams SL, Lee JT, Chang F, Bertrand FE, Navolanic PM, Terrian DM, Franklin RA, D'Assoro AB, Salisbury JL, Mazzarino MC, Stivala F and Libra M: Roles of the RAF/MEK/ERK and PI3K/PTEN/AKT pathways in malignant transformation and drug resistance. Adv Enzyme Regul 46: 249-279, 2006.

6 Brown KK and Toker A: The phosphoinositide 3-kinase pathway and therapy resistance in cancer. F1000Prime Rep 7: 13, 2015.

7 Maira SM, Pecchi S, Huang A, Burger M, Knapp M, Sterker D, Schnell C, Guthy D, Nagel T, Wiesmann M, Brachmann S, Fritsch C, Dorsch M, Chene P, Shoemaker K, De Pover A, Menezes D, Martiny-Baron G, Fabbro D, Wilson CJ, Schlegel R, Hofmann F, Garcia-Echeverria C, Sellers WR and Voliva CF: Identification and characterization of NVP-BKM120, an orally available pan-class I PI3-kinase inhibitor. Mol Cancer Ther 11: 317-328, 2012.
8 Bendell JC, Rodon J, Burris HA, de Jonge M, Verweij J, Birle D, Demanse D, De Buck SS, Ru QC, Peters M, Goldbrunner M and Baselga J: Phase I, dose-escalation study of BKM120, an oral pan-Class I PI3K inhibitor, in patients with advanced solid tumors. J Clin Oncol 30: 282-290, 2012.

9 Rodon J, Brana I, Siu LL, De Jonge MJ, Homji N, Mills D, Di Tomaso E, Sarr C, Trandafir L, Massacesi C, Eskens F and Bendell JC: Phase I dose-escalation and -expansion study of buparlisib (BKM120), an oral pan-Class I PI3K inhibitor, in patients with advanced solid tumors. Invest New Drug 32: 670-681, 2014.

10 Ando Y, Inada-Inoue M, Mitsuma A, Yoshino T, Ohtsu A, Suenaga N, Sato M, Kakizume T, Robson M, Quadt C and Doi T: Phase I dose-escalation study of buparlisib (BKM120), an oral pan-class I PI3K inhibitor, in Japanese patients with advanced solid tumors. Cancer Sci 105: 347-353, 2014.

11 Babb J, Rogatko A and Zacks S: Cancer phase I clinical trials: Efficient dose escalation with overdose control. Stat Med 17: 1103-1120, 1998.

12 Neuenschwander B, Branson M and Gsponer T: Critical aspects of the Bayesian approach to phase I cancer trials. Stat Med 27: 2420-2439, 2008.

13 Knight ZA, Gonzalez B, Feldman ME, Zunder ER, Goldenberg DD, Williams O, Loewith R, Stokoe D, Balla A, Toth B, Balla T, Weiss WA, Williams RL and Shokat KM: A pharmacological map of the PI3-K family defines a role for p110alpha in insulin signaling. Cell 125: 733-747, 2006.

14 Busaidy NL, Farooki A, Dowlati A, Perentesis JP, Dancey JE, Doyle LA, Brell JM and Siu LL: Management of metabolic effects associated with anticancer agents targeting the PI3K-AktmTOR pathway. J Clin Oncol 30: 2919-2928, 2012.

15 Shapiro GI, Bell-McGuinn KM, Molina JR, Bendell J, Spicer J, Kwak EL, Pandya SS, Millham R, Borzillo G, Pierce KJ, Han L, Houk BE, Gallo JD, Alsina M, Brana I and Tabernero J: Firstin-human study of PF-05212384 (PKI-587), a small-molecule, intravenous, dual inhibitor of PI3K and mTOR in patients with advanced cancer. Clin Cancer Res 21: 1888-1895, 2015.

16 Bendell JC, Kurkjian C, Infante JR, Bauer TM, Burris HA 3rd, Greco FA, Shih KC, Thompson DS, Lane CM, Finney LH and Jones SF: A phase 1 study of the sachet formulation of the oral dual PI3K/mTOR inhibitor BEZ235 given twice daily (BID) in patients with advanced solid tumors. Invest New Drug 33: 463471, 2015.

17 Hong DS, Bowles DW, Falchook GS, Messersmith WA, George GC, O'Bryant CL, Vo AC, Klucher K, Herbst RS, Eckhardt SG, Peterson S, Hausman DF, Kurzrock R and Jimeno A: A multicenter phase I trial of PX-866, an oral irreversible phosphatidylinositol 3-kinase inhibitor, in patients with advanced solid tumors. Clin Cancer Res 18: 4173-4182, 2012.

18 Markman B, Tabernero J, Krop I, Shapiro GI, Siu L, Chen LC, Mita M, Melendez Cuero M, Stutvoet S, Birle D, Anak O, Hackl $\mathrm{W}$ and Baselga J: Phase I safety, pharmacokinetic, and pharmacodynamic study of the oral phosphatidylinositol-3kinase and mTOR inhibitor BGT226 in patients with advanced solid tumors. Ann Oncol 23: 2399-2408, 2012.

19 Shimizu T, Tolcher AW, Papadopoulos KP, Beeram M, Rasco DW, Smith LS, Gunn S, Smetzer L, Mays TA, Kaiser B, Wick MJ, Alvarez C, Cavazos A, Mangold GL and Patnaik A: The clinical effect of the dual-targeting strategy involving $\mathrm{PI} 3 \mathrm{~K} / \mathrm{AKT} / \mathrm{mTOR}$ and RAS/MEK/ERK pathways in patients with advanced cancer. Clin Cancer Res 18: 2316-2325, 2012. 
20 Brown JR, Byrd JC, Coutre SE, Benson DM, Flinn IW, WagnerJohnston ND, Spurgeon SE, Kahl BS, Bello C, Webb HK, Johnson DM, Peterman S, Li D, Jahn TM, Lannutti BJ, Ulrich RG, Yu AS, Miller LL and Furman RR: Idelalisib, an inhibitor of phosphatidylinositol 3-kinase p110delta, for relapsed/ refractory chronic lymphocytic leukemia. Blood 123: 3390-3397, 2014.

21 Kahl BS, Spurgeon SE, Furman RR, Flinn IW, Coutre SE, Brown JR, Benson DM, Byrd JC, Peterman S, Cho Y, Yu A, Godfrey WR and Wagner-Johnston ND: A phase 1 study of the PI3Kdelta inhibitor idelalisib in patients with relapsed/refractory mantle cell lymphoma (MCL). Blood 123: 3398-3405, 2014.

22 Gopal AK, Kahl BS, de Vos S, Wagner-Johnston ND, Schuster SJ, Jurczak WJ, Flinn IW, Flowers CR, Martin P, Viardot A, Blum KA, Goy AH, Davies AJ, Zinzani PL, Dreyling M, Johnson D, Miller LL, Holes L, Li D, Dansey RD, Godfrey WR and Salles GA: PI3Kdelta inhibition by idelalisib in patients with relapsed indolent lymphoma. New Engl J Med 370: 1008-1018, 2014.

23 Kitagishi Y, Kobayashi M, Kikuta K and Matsuda S: Roles of PI3K/AKT/GSK3/mTOR pathway in cell signaling of mental illnesses. Depress Res Treat 2012: 752563, 2012.

24 Leibrock C, Ackermann TF, Hierlmeier M, Lang F, Borgwardt S and Lang UE: Akt2 deficiency is associated with anxiety and depressive behavior in mice. Cell Physiol Biochem 32: 766-777, 2013.

25 Beaulieu JM, Gainetdinov RR and Caron MG: Akt/GSK3 signaling in the action of psychotropic drugs. Annu Rev Pharmacol Toxicol 49: 327-347, 2009.

26 Karege F, Perroud N, Burkhardt S, Fernandez R, Ballmann E, La Harpe R and Malafosse A: Alterations in phosphatidylinositol 3-kinase activity and PTEN phosphatase in the prefrontal cortex of depressed suicide victims. Neuropsychobiology 63: 224-231, 2011.

27 Maira M, Schnell C, Lollini P, Chouaid C, Schmid P, Nanni P, Lam D, Di Tomaso E, Massacesi C and Rodon J: Preclinical and preliminary clinical activity of NVP-BKM120, an oral pan-class I PI3K inhibitor, in the brain. ESMO Congress 2012: Abstract 1675.

28 Mehnert A, Brahler E, Faller H, Harter M, Keller M, Schulz H, Wegscheider K, Weis J, Boehncke A, Hund B, Reuter K, Richard M, Sehner S, Sommerfeldt S, Szalai C, Wittchen HU and Koch U: Four-week prevalence of mental disorders in patients with cancer across major tumor entities. J Clin Oncol 32: 3540-3546, 2014.

29 Grassi L, Caruso R, Sabato S, Massarenti S, Nanni MG and The UniFe Psychiatry Working Group Coauthors: Psychosocial screening and assessment in oncology and palliative care settings. Front Psychol 5: 1485, 2015.
30 Sequist LV, Bell DW, Lynch TJ and Haber DA: Molecular predictors of response to epidermal growth factor receptor antagonists in non-small-cell lung cancer. J Clin Oncol 25: 587$595,2007$.

31 Janku F, Tsimberidou AM, Garrido-Laguna I, Wang X, Luthra R, Hong DS, Naing A, Falchook GS, Moroney JW, Piha-Paul SA, Wheler JJ, Moulder SL, Fu S and Kurzrock R: PIK3CA mutations in patients with advanced cancers treated with PI3K/AKT/mTOR axis inhibitors. Mol Cancer Ther 10: 558$565,2011$.

32 Janku F, Wheler JJ, Westin SN, Moulder SL, Naing A, Tsimberidou AM, Fu S, Falchook GS, Hong DS, GarridoLaguna I, Luthra R, Lee JJ, Lu KH and Kurzrock R: $\mathrm{PI} 3 \mathrm{~K} / \mathrm{AKT} / \mathrm{mTOR}$ inhibitors in patients with breast and gynecologic malignancies harboring PIK3CA mutations. J Clin Oncol 30: 777-782, 2012.

33 Ihle NT, Lemos R Jr., Wipf P, Yacoub A, Mitchell C, Siwak D, Mills GB, Dent P, Kirkpatrick DL and Powis G: Mutations in the phosphatidylinositol-3-kinase pathway predict for antitumor activity of the inhibitor PX-866 whereas oncogenic Ras is a dominant predictor for resistance. Cancer Res 69: 143-150, 2009.

34 Gonzalez-Angulo AM and Blumenschein GR Jr: Defining biomarkers to predict sensitivity to $\mathrm{PI} 3 \mathrm{~K} / \mathrm{Akt} / \mathrm{mTOR}$ pathway inhibitors in breast cance. Cancer Treat Rev 39: 313-320, 2013.

35 Vansteenkiste JF, Canon JL, Braud FD, Grossi F, De Pas T, Gray JE, Su WC, Felip E, Yoshioka H, Gridelli C, Dy GK, Thongprasert S, Reck M, Aimone P, Vidam GA, Roussou P, Wang YA, Di Tomaso E and Soria JC: Safety and efficacy of buparlisib (BKM120) in patients with PI3K pathway-activated non-small cell lung cancer: results from the phase II BASALT1 study. J Thorac Oncol 10: 1319-1327, 2015.

36 Higgins MJ, Jelovac D, Barnathan E, Blair B, Slater S, Powers P, Zorzi J, Jeter SC, Oliver GR, Fetting J, Emens L, Riley C, Stearns V, Diehl F, Angenendt P, Huang P, Cope L, Argani P, Murphy KM, Bachman KE, Greshock J, Wolff AC and Park BH: Detection of tumor PIK3CA status in metastatic breast cancer using peripheral blood. Clin Cancer Res 18: 3462-3469, 2012.

37 Fruman DA and Rommel C: PI3K and cancer: Lessons, challenges and opportunities. Nat Rev Drug Discov 13: 140-156, 2014.
Received August 2, 2016

Revised September 28, 2016 Accepted September 29, 2016 